\title{
Influence of whole Body Vibration Training on Strength Levels of Lower Limbsin Young Adults
}

\author{
Carlos Soares Pernambuco ${ }^{1,2 *}$, Sergio Medeiros Pinto ${ }^{1,2}$, Lucas Aleixo Dias da Costa ${ }^{1,2}$, and Juliana Costa \\ Brandao $^{3}$ \\ ${ }^{1}$ Postgraduate Program in Exercise and Sport Sciences, Brazil \\ ${ }^{2}$ Laboratory of Exercise Physiology, Brazil \\ ${ }^{3}$ Postgraduate Program in Exercise and Sport Sciences, Rio de Janeiro State University, RJ, Brazil
}

*Corresponding author: Carlos Soares Pernambuco, Laboratory of Exercise Physiology, Estacio de Sa University, Brazil.

Received Date: March 10, 2020

Published Date: March 30, 2020

\section{Abstract}

Objective: The aim of the present study was toanalyze the influence of the wholebody vibration (WBV) trainingon strength levels of lower limbs in young adults.

Method: The sample consisted of 13 sedentary individuals (age: $30 \pm 8.64$ years; BMI: $25.41 \pm 4.84 \mathrm{~kg} / \mathrm{m} 2$ ) of the male sex. Eight weeks of WBV training were conducted with 20 -minute vibration sessions using frequencies increasing from 15 to $30 \mathrm{~Hz}$, with 30 -second vibration exposure and 30-second rest. Every two minutes there was an increase in the frequency of $1 \mathrm{~Hz}$. Individuals were instructed to stand in the orthostatic position with their feet shoulder width apart, knees flexed at 120 degrees, arms extended, holding firmly in the machine's hand rests. The procedure was performed twice a week with a one-day interval. The strength was evaluated througha dorsal dynamometer in squatting and plantar flexion exercises.

Result: There were significant strength gains in the muscles involved in squatting $(\mathrm{p}=0.0001)$ and plantar flexion $(\mathrm{p}=0.024)$ exercises after 8 weeks of intervention. Conclusion: It was possible to observe that the whole body vibration training promoted an improvement in lower limb strength levels in the execution of the analyzed exercises.

Keywords: Muscle strength; Whole body vibration; Lwer limbs

\section{Introduction}

Vibration is a periodic, sinusoidal and deterministic mechanical stimulus characterized by an oscillatory movement. Vibrations are also generated through a vibrating platform when there is a direct contact of a person, usually standing in the base of this type of equipment. The vibration that is produced in these machines is transmitted to the body of the subject, producing stimuli of whole body vibration (WBV) [1, 2].

Biomechanical parameters such as frequency and amplitude of sinusoidal vibration can be manipulated in the clinical procedure and in the prescription of the stimulus for exercise.The duration of the exercise, as well as the rest time, the number of sets in a session and the number of sessions are also controlled.All of these variables depend mainly on the clinical and physical conditions of the individualBressel, Smith [3].

It has been proposed that the vibratory platform stimulus involves monosynaptic reflexes, which are induced by the stretchshortening action of the muscle fibers acting on the joints in which the vibration is being absorbed.These stimuli reach the autonomic nervous system and the vestibular system. When it acts on the vestibular system, it sends stimuli to the muscle spindles, causing small contractions, probably causing increased levels of muscular strength Cardinale and Wakeling [1,4,5].

Pioneering studies with WBV aiming at improving athletic performance occurred with professional ballet dancers to recover 
injuries and increase jumping height and, later, in Russian Olympic athletes [6]. Since then, it has been observed that muscle stimuli through WBV increase mechanical strength in elite athletes [1,7] and even in populations with a medical condition [8]. Vibratory stimuli stimulate the muscle spindles, resulting in the activation of the $\alpha$-type neurons, causing muscular contraction Furness and Maschette [9]. Thus, it is possible to assume that WBV can potentiate muscle contractions, increasing performance as in traditional training. Thus, the aim of the study was to verify whether WBV training promotes improvement in lower limb strength levels in young adults.

\section{Methods}

This is a quantitative experimental type study. Individuals of both sexes were invited to participate in the present research through pamphlets placed in the Physiotherapy school clinic of Estácio de Sá University- Cabo Frio, RJ, Brazil.The present study used the following inclusion criteria: a)to be an undergraduate of physiotherapy at the mentioned university; b)age between 20 and 50 years old; c) do not present any diagnosed healthy problem; d)to be physically fit to perform the battery of tests, without physical limitations, without the use of stimulant drugs, or dietary supplements that promote lean body mass gain.The exclusion criteria were: a) to be absent in more than $20 \%$ of the training sessions; b) use of prostheses and orthoses; c)to present neurological and motor changes both of permanent effect caused by some disease, and of a provisional effect due to the use of drugs that affect the neuro motor system and any other acute or chronic condition that would prevent or limit the performance of the battery of tests; d) to present a positive PAR-Q [10].

After the sample captation process, 13 male subjects were selected. The research was carried out with the approval of the research ethics committee of the Estácio de Sá University, under the number 1.617.605.The volunteers who agreed to participate in the present study signed an informed consent form in accordance with the guidelines regarding human research delineated in Resolution 466/2012 of the National Health Council (BRASIL, 2013).

The description of the sample includes measurements of body mass and height. The measurement of body mass (expressed in kg) was performed on a mechanical scale (Filizola, Brazil) and stature (expressed in $\mathrm{cm}$ ) using a portable stadiometer (Seca, Baystate Scale \& Systems, USA). In addition, we calculated the body mass index (BMI) as the ratio between the body mass and the square of the stature $\left(\mathrm{kg} / \mathrm{m}^{2}\right)[11]$.

\section{Assessment of muscle strength}

The static strength test was performed with a dorsal dynamometer(Back Strength Dynamometer T.K.K.5002 BackA,Japan). Prior to the tests, all participants were instructed on how the dynamometer works. The test was standardized in three maximum trials, followed by a one-minute recovery interval. To begin the test, the lower limbs should be semi-flexed [12].
It was measured the strength of the muscles involved in squatting and plantar flexion exercises. To verify the muscles involved in the squat exercise, the individual was instructed to stand with flexed knees at $120^{\circ}$ and with the spine erect, hold firmly on the dynamometer bar, look forward and keep the shoulders aligned with a small scapular retraction. When advised, the individual should lift using only the strength of the lower limbs. This position should be maintained for 3 seconds in maximum static contraction. For evaluation of the muscles involved in the plantar flexion exercise, the individual should be positioned fully erect with shoulders aligned and a small scapular retraction. At the evaluator signal, the individual should do a plantar flexion movement, remaining 3 seconds in this position in maximum static contraction. The static strength evaluation occurred in three moments: baseline, after the $4^{\text {th }}$ week and at the end of the intervention period.

\section{Intervention}

The WBV training were performed on a vibratory platform (Treo Fitness V209), following the protocol used by [13],which consists of 20 minutes of vibration using increasing frequencies of 15 to $30 \mathrm{~Hz}$, with 30 seconds of vibration exposure and 30 seconds of rest. Every two minutes there was an increase in the frequency of $1 \mathrm{~Hz}$. Individuals were instructed to stand in the orthostatic position with feet shoulder width apart, with slightly flexed knees $\left(120^{\circ}\right.$ knee angle), arms outstretched, holding firmly in the hand supports of the machine. The intervention was performed twice a week with a one-day interval to avoid fatigue. The period of intervention lasted eight weeks, totaling 16 sessions. There were no reports of adverse side effects to the procedures.

\section{Statistical analysis}

Data were analyzed by SPSS 20 for Windows and presented as mean and standard deviation for descriptive statistics. Shapiro-Wilk and Levene tests were used to verify the normality and variance homogeneity of the sample data, respectively. In the inferential statistics, it was applied the analysis of variance (ANOVA one-way), with the Tukey post-hoc to identify possible differences between the analyzed variables. The study established $\mathrm{p}<0.05$ for statistical significance.

\section{Result}

Table 1: Characteristics of the sample.

\begin{tabular}{|c|c|c|c|}
\hline & Mean & SD & P-Value (14) \\
\hline Age (years) & 30 & 8.64 & 0.08 \\
\hline Body mass $(\mathrm{kg})$ & 1.74 & 0.08 & 0.734 \\
\hline Height $(\mathrm{cm})$ & 174.44 & 8.51 & 0.322 \\
\hline BMI $(\mathrm{kg} / \mathrm{m} 2)$ & 25.41 & 4.84 & 0.284 \\
\hline
\end{tabular}

SD: standard deviation, SW: Shapiro Wilk, BMI: Body mass index

Table 1 shows the descriptive characteristics of the sample (Table 1). Figure 1 shows the results in the strength levels in the squat and plantar flexion exercises in the three evaluations: pretest, after the fourth week and after the last session of the eighth 
week of intervention. According to the results, it was possible to observe a significant increase in strength levels for the muscles involved in the squat exercise $(\mathrm{p}<0.001)$ and the plantar flexion exercise $(\mathrm{p}=0.024)$ after the eight week of intervention (Figure 1) [14].

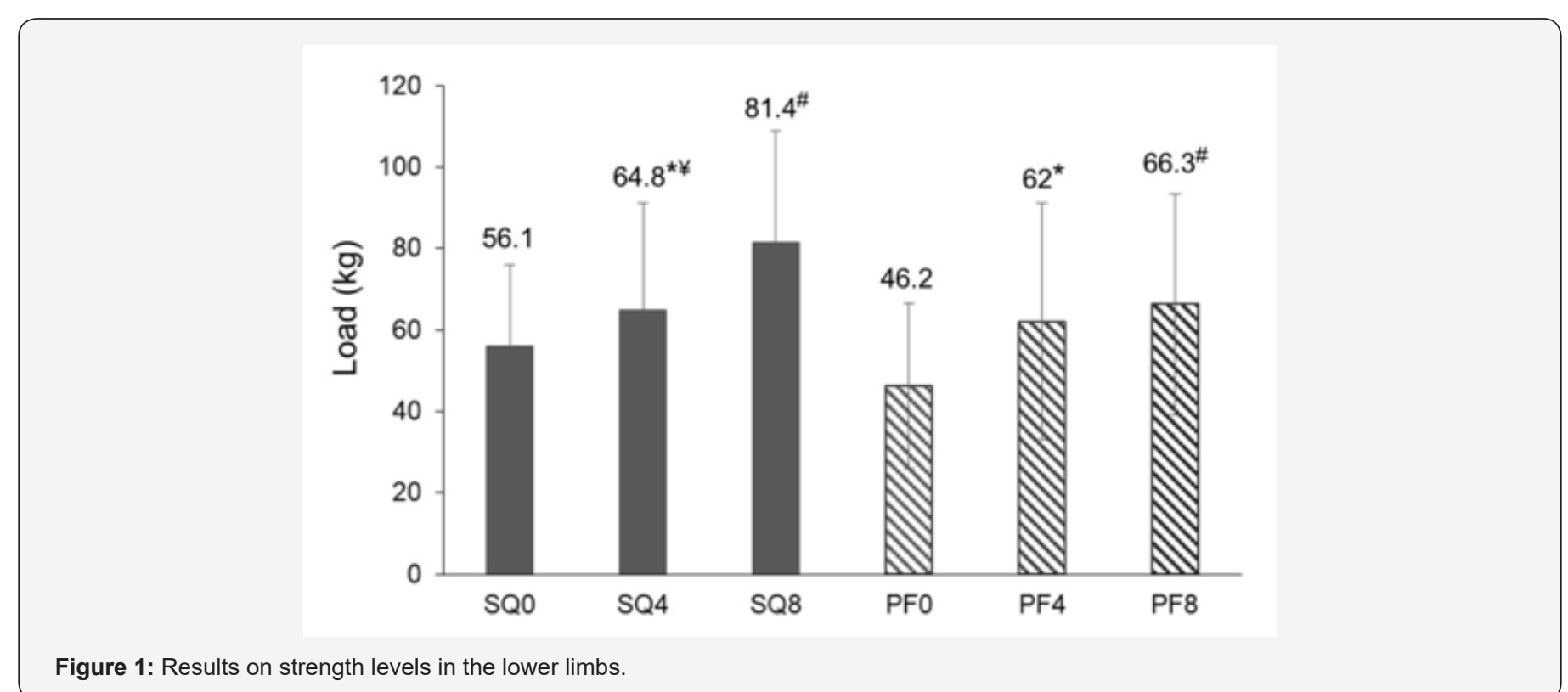

Legend: SQ: squat exercise; PF: plantar flexion exercise; 0: pre-test; 4: test of the $4^{\text {th }}$ week; 8: post-test; ${ }^{*}$ significant difference between pre-test and test of the $4^{\text {th }}$ week; $¥$ significant difference between test of the $4^{\text {th }}$ week and post-test; \# significant difference between pre-test and post-test; $\mathrm{p}<0.05$.

\section{Discussion}

The results of the present study showed a significant difference on strength levels of the muscles involved in squat and plantar flexion exercises after the period of 4 and 8 weeks of intervention. The muscle performance increase after a short period of vibration training has been compared with what happens after several weeks of heavy resistance training $[15,16]$.

The influence of resistance training on neuromuscular properties of skeletal muscle are well known [17]. This knowledge may help to interpret and understand the vibration findings in the current study. Therefore, voluntary strength performance is determined by intramuscular factors and by the extent of neural activation. This is due the training-induced changes in the nervous system (neural adaptation), which allow more complete activation of the prime movers of a specific movement and better coordination of the activation of the relevant muscles [7].

Thus, the neural adaptation is the first response mechanism of a skeletal muscle to resistance training [18]. Changes in the neural factors in response to training occur within a few months, whereas changes in the morphological structure of the muscle take longer time. This way, specific adaptation to training strongly depends on the training program performed [17].

Studies performed with the frequency around 15 to $30 \mathrm{~Hz}$ obtained significant results for the strength level with the WBV training, as found in the present study [13,19-21]. However, other studies did not show significant changes in power and strength levels of lower limbs with WBV training with a frequency of 20 to $35 \mathrm{~Hz}$ [22-25].

Paradisis et al. [20] observed a significant improvement in 24 athletes. In the vibration group ( $\mathrm{n}=12$ ), the WBV training induced significant improvement of the strength of the knee extensors $(p<0.001)$, the vertical-jump performance $(p<0.001)$ and flexibility $(\mathrm{P}<0.001)$ after 8 weeks of training. The weeks of intervention are in accordance with those used in the present study, strengthening the results found. The study by Fagnani et al. [21], at the end of eight weeks, also demonstrated a significant improvement in the peak of dynamic strength $(p<0.05)$ of 24 athletes submitted to WBV training ( $35 \mathrm{~Hz}$ and $\pm 4 \mathrm{~mm}$ ), in a $90^{\circ}$ of knee flexion. The weeks of intervention and positioning of the semi-flexion knees demonstrate similarities with present study.

Cardinale and Lim [19], in electro myographic analysis, found a positive response at $30 \mathrm{~Hz}$, suggesting that this frequency causes a greater response in the lateral muscle of the leg muscle during the low squat vibration treatment. The frequency used in the present study is in accordance with those used in this study [19] and knee positioning also strengthens the positive findings. Torvinen et al. [13] concluded that in a single application of WBV intervention can improve lower limb muscle performance and body balance in healthy young adults. The frequencies used are in accordance with the ones that were applied in the present study, coinciding with the results achieved.

Ruiter et al. [25] verified the effects of 11 weeks of WBV training ( $30 \mathrm{~Hz}$ and $8 \mathrm{~mm}$ ) on the isometric strength performance in 20 individuals. Comparing with the group that performed equal movements outside the vibratory platform, no significant differences were observed in any of the mentioned parameters. 
Bazzet-Jones et al. [22] evaluated that the positive effects of WBV training on the improvement of physical and muscular performance are temporary, lasting only between five to ten minutes after training, thus limiting to short-term adaptations and not being maintained for long periods. In the group observed in the present study, the strength level of the muscles involved in the squat exercise obtained increasing improvements, demonstrating that there was no loss or fall in the strength levels.

Mileva et al. [26] demonstrated that low frequencies of WBV training $(30 \mathrm{~Hz})$ led to neural plasticity, increasing the excitability of the corticospinal pathway, supporting the likelihood of neural adaptations. In contrast, the study by Colson et al. [23] demonstrated that voluntary muscle activation of knee extensors remained unchanged by WBV training and that, regardless of intervention, maximal voluntary isometric contraction was reduced. In the group observed in the present study, the intervention took 8 weeks, demonstrating that it is possible to achieve positive results in a shorter period [27].

One of the limitations of the present study was the lack of control of the periodization of the training and the position to which the subjects were submitted throughout the study, which may have an impact on the results. An electromyography evaluation of the muscle activation pattern could provide more consistent parameters regarding neuromuscular adaptations throughout the procedures, which can also be pointed out as a limitation. It is suggested that future studies include this variable and measure the influence of WBV training on the strength levels more accurately.

\section{Conclusion}

Based on the results obtained in this study, it was possible to observe that the WBV training can contribute to the gain of strength of the lower limbs, both for the muscles involved in the squat exercise, as well as in the plantar flexion in sedentary men.

\section{Acknowledgement}

None.

\section{Conflicts of Interest}

There is no conflict of interest among the researches.

\section{References}

1. Adams R (1999) Revised physical activity readiness questionnaire. Can Fam Physician 45 (992-995): 1004-1005.

2. Bazett-Jones DM HW, Dugan EL (2008) Comparing the effects of various whole-body vibration accelerations on counter-movement jump performance. J Sports Sci Med 7(27): 144-150.

3. Bosco, C, Cardinale, M.; Tsarpela, O (1999) Influence of vibration on mechanical power and electromyogram activity in human arm flexor muscles. Eur J Appl PhysiolOccup Physiol 79(4): 306-311.

4. Bosco C, Colli R, Introini E, Cardinale M, Tsarpela O, et al. (1999) Adaptative responses of human skeletal muscle to vibration exposure. Clin Physiol 19(27): 183-187.

5. Bosco C, Cardinale M, Tsarpela O, Colli R, Tihanyi J, et al. (1998) The influence of whole body vibration on the mechanical behaviour of skeletal muscle. Biol Sport 153: 157-164.
6. Brasil. (2013) National Health Council. Diario Oficial da Uniao, Brasilia, DF, 12(59).

7. Bressel E, Smith G, Branscomb J (2010) Transmission of whole body vibration in children while standing. Clin Biomech 25(27): 181-186.

8. Cardinale M, Lim J (2003) Electromyography activity of vastus lateralis muscle during whole-body vibrations of different frequencies. J Strength Cond Res 17(3): 621-624.

9. Cardinale M, Wakeling J (2005) Whole body vibration exercise: are vibrations good for you? Br J Sports Med 39(9): 585-589.

10. Carroll TJ, Riek S, Carson RG (2001) Neural adaptation to resistance training: implication for movement control. Sports Med 31(27): 829840.

11. Colson SS, Petit PD, Hebreard L, Tessaro J, Pensini M (2009) Whole body vibration does not enhance muscle activation. Int J Sports Med 841-844.

12. Cormie P, Deane RS, Triplett NT, Mcbride JM (2006) Acute effects of whole-body vibration on muscle activity, strength, and power. J Strength Cond Res 20: 257-261.

13. Dionello CF, Souza PL, Sa-Caputo D, Morel DS, Moreira-Marconi E, et al. (2017) Do whole body vibration exercises affect lower limbs neuromuscular activity in populations with a medical condition? A systematic review. Restor Neurol Neurosci 35(6): 667-681.

14. Fagnani F, Giombini A, Di Cesare A, Pigozzi F, Di Salvo V (2006) The effects of a whole-body vibration program on muscle performance and flexibility in female athletes. Am J Phys Med Rehabil 85(12): 956-962.

15. Furness TP, Maschette WE (2009) Influence of whole body vibration platform frequency on neuromuscular performance of communitydwelling older adults. J Strength Cond Res 23(5): 1508-1513.

16. Hakkinen K, Komi P (1985) Effect of explosive type strength training on electromyographific and force production characteristics of leg extensors muscles during concentric and various stretch-shortening cycle exercises. Scand J Sports Sci 7: 65-76.

17. De Lecluse C, Roelants M, Verschueren S (2003) Strength increase following whole body vibration compared to resistance training. Med Sci Sports Exerc 35:1033-1041.

18. Johnson BL, Nelson JK (1979) Practical measurements for evaluation in Physical Education. Minnesota: Burgess Publishing Company.

19. Marfell-Jones M, Olds T, Stewart A, Carter L (2006) International standards for anthropometric assessment. Potchefstroom, South Africa: ISAK.

20. Mileva KN, Bowtell JL, Kossev AR (2009) Effects of low-frequency wholebody vibration on motor-evoked potentials in healthy men. Exp Physiol 94: 103-116.

21. Nazarov V, Spivak G (1987) Development of athlete's strength abilities by means of biomechanical stimulation method. Theory and Practice of Physical Culture (Moscow) 12(37-39).

22. Paradisis G, Zacharogiannis E (2007) Effects of whole-body vibration training on sprint running kinematics and explosive strength performance. J Sports Sci Med 6(1): 44-49.

23. Rittweger J (2010) Vibration as an exercise modality: how it may work, and what its potential might be. Eur J Appl Physiol 108(5): 877-904.

24. Rittweger JM, Mutschelknauss D (2003) Felsenberg. Acute changes in neuromuscular excitability after exhaustive whole body vibration exercise as compared to exhaustion by squatting exercise. Clin Physiol Funct Imaging 23(2): 81-86.

25. Roll JP, Vedel JP, Ribot E (1989) Alteration of proprioceptive messages induced by tendon vibration in man: a microneurographic study. Exp Brain Res 76(1): 213-222.

26. De Ruiter, Sale D (1988) Neural adaptation to resistance training. Med Sci Sports Exerc 20: 135-145.

27. Santos-Filho SD, Cameron MH, Bernardo-Filho M (2012) Benefits of whole-body vibration with an oscillating platform for people with multiple sclerosis: a systematic review. Mult Scler Int 274728: 1-6. 